E3S Web of Conferences 1, 22003 (2013)

DOI: $10.1051 / \mathrm{e} 3$ sconf $/ 20130122003$

(C) Owned by the authors, published by EDP Sciences, 2013

\title{
Reactivity of urban environments towards legislative actions. The case of Roma (Italy)
}

\author{
$\underline{\text { R. Salzano }}^{1}$ and M. Angelone ${ }^{2}$ \\ ${ }^{1}$ CNR, Institute for Atmospheric Pollution. Resarch Area 1, via Salaria km 29.300, 00016 Monterotondo Scalo (RM). \\ salzano@iia.cnr.it \\ ${ }^{2}$ ENEA, C.R. Casaccia. PROT CHIM, Via Anguillarese 301, 00060 Roma.massimo.angelone@enea.it
}

\begin{abstract}
The investigation of sediment chronostratigraphy was performed in order to reconstruct heavy metals $(\mathrm{Pb}, \mathrm{Cd}, \mathrm{Cu}$, and $\mathrm{Zn})$ and major elements $(\mathrm{Fe}, \mathrm{Al}$ and $\mathrm{Mn})$ fluxes in a heavy traffic site located in Roma (Italy). This city represents an ideal situation from a geochemical point of view (outcropping rocks are enriched rocks in terms of heavy metals content) where anthropic emissions are exclusively associated to traffic and heating systems. The impact of biological activity and soil erosion on sedimentation process were investigated in one urban lake, where the sedimentation model was defined using radiometric determinations $\left({ }^{137} \mathrm{Cs}\right.$ and unsupported ${ }^{210} \mathrm{~Pb}$ ). Fluxes calculations and isotopic composition of lead were performed in order to enhance the metal distribution through the collected core. Statistical analysis allowed discriminating elements in two main groups: traffic related metals and urban aero-disperse elements. Indexes, which can estimate the elemental affinity to the urban dust, were calculated for metal source definition. Lake sediments recorded the fall of $\mathrm{Pb}$ air content that occurred after leaded gasoline phasing out and after about 10 years the total amount of $\mathrm{Pb}$ decreased of about $90 \%$.
\end{abstract}

Key words: $\mathrm{Pb}$ isotopes, Heavy metals, Lake sediments.

\section{Introduction}

Public agencies and local administrations are nowadays focused on improving air-monitoring systems and defining safe levels of exposure towards urban pollution. At the same time governments have provided important regulations aimed to increase air quality and health safety in big cities. Technologic improvements have allowed until now reducing toxic emissions from large-scale productions, as indicated by national and international protocols like the UNECE LRTAP (Long-Range Transboundary Transport of Air Pollutant) Convention (Verstreng et al. 2006). Unfortunately the latest inventories of heavy metals released in Europe are lacking on estimating local contributions from "natural" sources that sometimes are relatively considerable. Recent studies estimated that the natural contribution to PM may range from $5 \%$ to $50 \%$ in different European Countries. The natural background level shows regional variations, and in many cases (in particular for the Southern Mediterranean Countries) naturally emitted particulate matter may cause exceeding of air quality standards (Marelli 2007). The consequences of this "natural" anomalous levels are legal actions against Member States, that usually make prevention with traffic bans that are quite unpopular and cost effective. Considering all these aspects, the correct management of an urban environment implies to have a deep knowledge about how it responses towards anthropic actions. These data are also necessary to define safe levels adapted to local conditions and to demonstrate that exceeding is naturally caused. This study presents an approach based on the characterization of lake sediments, which represents an important environmental proxy of urban atmosphere changes as the fall-out of urban particulate matter accumulated in sediments. The reconstruction of sediment chrono-stratigraphy permits to evaluate atmospheric pollution variations and understand how the urban environment can react to anthropic activities. The study site is located in Roma (Italy), one of the biggest European cities (with about 2,700,000 residents widespread on a 360 square kilometres wide district) and where large industrial or thermo-electric plants are far from the centre. The major source of atmospheric pollution in the metropolitan area is vehicular traffic, considering that more than $2,000,000$ vehicles daily 
circulate. The presence of toxic metals in urban environment $(\mathrm{Pb}, \mathrm{Cd}, \mathrm{Zn}, \mathrm{Cu}, \mathrm{Mn}$ and $\mathrm{Fe})$ in trafficassociated particles is well documented (Fergusson 1990) and there is a strict relationship between hospitalisations, mortality and particulate exposure (Michelozzi et al. 1998). The aim of this study is also to test the effects of local peculiar geological features on urban environments. Roma is in fact located between two volcanic complexes and the airborne matter is constituted partly by minerals produced by alteration of outcropping rocks. Considering that volcanic products have generally high heavy metals content, the urban background of these elements will be naturally elevated without any anthropic contribution.

\section{Study Area}

The area of Roma (Italy) was investigated considering one artificial lake located inside the city. This lake (Lago dell'EUR) was built in 1960 for the Olympic games with a $85,200 \mathrm{~m}^{2}$ surface and a $3 \mathrm{~m}$ maximum depth. The artificial basin is completely isolated from surrounding soils and bedrock by a concrete lodgement coupled to a runoff-waters collection system. The water supply is powered by a private aqueduct and the water output is collected only when the lake surface exceeds a fixed level. The basin is located inside the high-density urban texture of Rome and an heavy traffic road (more than 100,000 vehicles/day) passes over the lake. In conclusion, since the lake was built no restoration works were done.

\section{Methods}

Sediments sampling in Lago dell'EUR was performed in 2002 using a piston corer. The mineralogical composition was investigated by powder X-Ray Diffraction. Sediments samples were oven dried $\left(24 \mathrm{~h}\right.$ at $\left.105^{\circ} \mathrm{C}\right)$ and sieved at $0.5 \mathrm{~mm}$. The estimation of organic matter content was obtained performing the loss of ignition determination at $550^{\circ} \mathrm{C}$; Silica and $\mathrm{P}$ contents were determined by UV-Vis spectrometry; while $\mathrm{CO}_{3}{ }^{=}$amount was investigated using a gas-volumetric method. The sediment chrono-stratigraphy was defined measuring radionuclide activities by $\boldsymbol{\gamma}$-spectrometry and two independent methods were used to calculate sedimentation rates: one based on evaluating ${ }^{210} \mathrm{~Pb}$ fluxes from the atmosphere; one based on estimating ${ }^{137} \mathrm{Cs}$ fallout. The elemental composition of sediments was obtained digesting samples with a $\mathrm{HF}-\mathrm{HClO}_{4}$ solution and determining $\mathrm{Ca}, \mathrm{Mg} \mathrm{Al}, \mathrm{Fe}, \mathrm{Ba}, \mathrm{Zn}, \mathrm{Cu}, \mathrm{Pb}$ and $\mathrm{Cd}$ contents by ICP-OES and HGA-AAS. Pb stable isotopes were determined by TIMS.

\section{Results}

Considering the good isolation of the studied basin from runoff waters, the adduction input of $30-60 \mathrm{l} / \mathrm{s}$ and lakesurface evaporation, the water residence time in the lake is about two hundreds days. This low refreshing time and the adduction of nutrient rich waters cause eutrophication of the lake, where the effects are massive presence of algae and modification of water chemistry toward a depositional behaviour. Two main groups of algae are present in the water body and control sediment deposition: green algae and diatoms. This last organisms don't affect water chemistry but contribute to sedimentation with a massive accumulation of siliceous shells. In conclusion these sediments are constituted by a massive authigenic phase (precipitated calcite and diatom shells) with a low detritic fraction. The detritic component (recognizable by Al presence) is probably mainly composed by "urban dust" (particles from vehicles emissions, building erosion materials, carbonaceous particles produced by heating systems etc.) and "natural particles", mainly derived from soil and rocks erosion (Perrino et al. 2007).

${ }^{210} \mathrm{~Pb}$ and ${ }^{137} \mathrm{Cs}$ methods allow reconstructing core chronostratigraphy, which represent a 40 years time interval starting since 1960 to 2002. The first approach evidenced the presence of two distinct sedimentation phases. A precise rate estimation comes out using ${ }^{137} \mathrm{Cs}$ method which evidenced a well-defined peak in the 44-48 $\mathrm{cm}$ depth interval, which can be associated to the Chernobyl accident and consequently to 1986 . This data confirms what ${ }^{210} \mathrm{~Pb}$ method suggested and the calculated values fall inside ${ }^{210} \mathrm{~Pb}$ ranges $(\mathrm{Top}=2.7 \mathrm{~cm} / \mathrm{yr}-$ Bottom $=1.5 \mathrm{~cm} / \mathrm{yr})$. Coupling this data to bathymetric measurements made by the local authority in 1967 and 1977, sediment thickness has been increased constantly since 1960 to nowadays following a sinusoidal sedimentation rate changing. The controlling process that can be invoked is eutrophication, which is influenced by nutrients availability, water supply reduction and increasing water residence time. The relationship between rate variations and $\mathrm{P}$ sediment content suggests that both algal groups (Green algae and Diatoms) are responsible of the heavy biological activity occurring in the lake.

The statistical data mining allowed us to group elements as "dusty" related elements (Al, Fe, Na, K, Mn, $\mathrm{Ba}, \mathrm{Cu}$ and $\mathrm{Zn})$ "traffic" related metals $(\mathrm{Pb}, \mathrm{Cd})$ and "authigenic" components $\left(\mathrm{SiO}_{2}, \mathrm{CO}_{3}{ }^{=}, \mathrm{Ca}\right.$ and $\left.\mathrm{Mg}\right)$. The first group is associated with dust atmospheric flux and relative elements are contained on lithogenic minerals and particles produced by alteration of urban artefacts, transported by wind and felled out in the lake. Scattered distribution of all these elements is evidence of a not constant atmospheric flux, which is influenced by seasonal climate changes, urbanization, anthropic activities, etc. Traffic related elements, that are associated with particles emitted from vehicles exhausts, are lead, that is emitted in the atmosphere as constituents of halide compounds (Fergusson 1990), and cadmium, which is mainly associated to brake pads (Canepari et al. 2008). Moreover, these elements are associated with reactive phases that can involved in particulate-water interactions and that can be accumulated in sediments as constituents of the authigenic phases. In the urban environment the circulation model of traffic-related elements is complex and it is influenced by many factor as weather variations, run-off, surface creep, saltation etc. owing to the 
phenomena of deposition and resuspension. In addition of that, the presence of such metals can also be affected by variations in gasoline composition and traffic intensities. The third group represents the product of biological activity. LOI is an index of organic matter content, $\mathrm{SiO}_{2}$ is evidence of diatom activity and carbonate content and relative cations are produced by the green algae activity, that alter the water chemistry. Temperatures variations and water residence time are, especially in this case, controlling parameters. All ' 60 s fluxes are generally 2.5 times higher than recent values and this is probably related to the strong urbanization and expansion of EUR area during that period. EUR was, in fact, before the ' 60 Olympic games a very peripheral zone of Roma, where few buildings and young implanted vegetation constituted the landscape of this new urban area of Roma. The direct consequence was that constructions and works acting in this district generated massive air dust load in the low troposphere that was continuously resuspended in the air. "Traffic elements" differ from "dusty metals" as that they show a less decreasing trend (just 1.5 times lower). This could be explained since that increasing vehicle circulation happened during those years in opposition of the previous described "urbanization effect". Elements source definition can be improved adding, to this data treatment, the calculation of an index defined as "Dust source affinity" (DA) (Fig. 5), which is a mathematic expression of what diagrams shows intuitively. Defining $\mathrm{DA}$ as $(\mathrm{Me} / \mathrm{Al})_{\mathrm{x}} /(\mathrm{Me} / \mathrm{Al})_{\text {mean }}$, where $\mathrm{Me}$ is the considered metal and $\mathrm{Al}$ represents the reference element for atmospheric dust fluxes, it is possible to estimate metal affinity to atmospheric dust and consequently elemental origin. $\mathrm{Fe}, \mathrm{Ba}, \mathrm{Mn}$ show a great affinity with $\mathrm{Al}$, while $\mathrm{Pb}$ and $\mathrm{Cd}$, on the other hand, show an high variable DA with increasing ratios during recent years that exclude an "adduction" origin of those metals (their water content is very low), while it is evident the role of "traffic" impact on urban aerosol. The vehicular origin is more evident normalizing $\mathrm{Pb}$ flux towards $\mathrm{Cd}$ flux and the so called "lead rise and fall" effect, happened in the ' $90 \mathrm{~s}$ as a consequence of the introduction of unleaded gasoline, is well defined observing $\mathrm{Pb}$ stable isotopes. Considering gasoline fingerprints and local rock isotopic compositions it can estimated that gasoline contribution to lead pollution passed from $50 \%$ to less than $10 \%$ in 40 years and that 10 years after the catalyst were made mandatory for Italy, the isotopic ratios and the $\mathrm{Pb} / \mathrm{Cd}$ ratio fell towards values close to those of rock and $60 \mathrm{~s}$, respectively.

All these observations imply that atmospheric fluxes are not homogenous all over the city and that aerosol compositions are dominantly controlled by urban texture density and by outcropping rocks, which are the main dust source. Moreover, strong differences, in terms of heavy metals contribution, can be expected between volcanic products emitted by the Alban Hills Complex (outcropping in the south-eastern part of the city), from those erupted by the Sabatinian Complex (dispersed on the northern side of the city) and sedimentary deposits accumulated before, during and after the volcanic activity (Salzano 2006, Salzano et al. 2008).

\section{Conclusions}

This work evidenced that lake sediment studies are a good way to reconstruct heavy metals pollution during time in an urban environment and that ${ }^{210} \mathrm{~Pb}$ and ${ }^{137} \mathrm{Cs}$ dating methods can provide a good sedimentation model, with which it is possible to define sediment chronostratigraphy. The elemental analyses outlined a sedimentation processes involving Lago dell'EUR, that can be considered as an eutrophic pond where metal fluxes reflect atmospheric fall-out. It has been possible to identify metal sources (traffic and wind erosion) and relative fluxes: $\mathrm{Pb}$ and $\mathrm{Cd}$ are strictly associated to vehicular exhaustion and could be used as traffic index of pollution; $\mathrm{Al}, \mathrm{Mn}$ and Fe could be used to index dust fluxes related to airborne material (rock minerals or urban degradation products); other metals ( $\mathrm{Cu}$ and $\mathrm{Zn})$ unfortunately are emitted by different sources, which hardly can be estimated. Sediments recorded total dust fluxes occurred in the urban atmosphere and permitted, for example, to reconstruct air lead content in the urban atmosphere and to observe the $\mathrm{Pb}$ fall down occurred after leaded gasoline phasing out (lead air content has been decreased after 10 years of about 90\%). A not negligible natural amount of heavy metals is present in the urban atmosphere but only additional analyses will complete this estimation. This work demonstrated that lake sediments studies are a potential useful tool for local administrations to improve urban environment knowledge and to calibrate actions aimed to increase air quality.

\section{Acknowledgements}

The authors thank INAIL and University of Roma TRE for the financial and logistic support provided during the project between 2002 and 2005. The TIMS analyses have been carried out in collaboration with D. Pyle and K. Rubin, SOEST - University of Hawaii.

\section{References}

Canepari S, Perrino C, Olivieri F, Astolfi ML. Characterisation of the traffic sources of PM through size-segregated sampling, sequential leaching and ICP analysis. Atmos Environ 2008; 42:8161-8175.

Fergusson JE. The heavy elements: chemistry, environmental impact and health effects. New York; Pergamon Press Inc.; 1990.

Marelli L. Contribution of natural sources to air pollution levels in the EU - a technical basis for the development of guidance for the Member States EUR 22779; 2007. 
Michelozzi P, Forastiere F, Fusco D, Peducci CA, Ostro B, Ancona C, Pallotti G. Air pollution and daily mortality in Rome, Italy. Occup Environ Med 1998; 55(9):605-610.

Perrino C, Canepari S, Cardarelli E, Catrambone M, Sargolini T. Inorganic constituents of urban air pollution in the Lazio region (Central Italy). Environ Monit Assess 2007; 128:133-151.

Salzano R. Spatial and chronological analyses of heavy metals pollution in an urban environment: the case of Roma. Comparison between different monitoring techniques. Plinius 2006; 32:222-228.
Salzano R, Angelone M, Sprovieri F. Caratterizzazione geochimica dei suoli dell'area romana. Mem descrittiva Cart Geol d'Italia 2008; 80:51-64.

Verstreng V, Rigler E, Adams M., Kindbom K, Pacyna $\mathrm{JM}$, van der Gon HD, Reis S, Travnikov O. Inventory review 2006. Oslo; EMEP: Technical Report MSC-W 1; 2006.

Ziemacki G, Cattani G, Cusano MC, Stacchini G, Marconi A. Contenuto di metalli nelle varie frazioni dimensionali di materiale particellare. Ann Ist Super Sanità 2003; 39 (3):371-379. 